\title{
ДЕЙСТВИТЕЛЬНАЯ НАЛОГОВАЯ ОБЯЗАННОСТЬ НАЛОГОПЛАТЕЛЬЩИКА: ПРОБЛЕМЫ ОПРЕДЕЛЕНИЯ В СУДЕБНОЙ ПРАКТИКЕ
}

\section{SUBSTANTIAL TAX OBLIGATION OF A TAXPAYER: PROBLEMS OF DEFINITION IN JUDICIAL PRACTICE}

V. Golenev

Summary: This article is devoted to the problem of determining the substantial tax obligation (actual tax liability). In the tax code of the Russian Federation, this issue remained unresolved, which subsequently led to widespread legal proceedings regarding the actual amount of tax liability. Courts have applied tax law in different ways in situations of uncertainty about tax liability. In the article: the issue of additional taxes in excess of the contract prices offset the single tax under the simplified system of taxation on account of income tax applied for "business fragmentation", and incorrect calculation of the tax on the actual amount of tax obligations results of the tax audit (neglect all costs "scheme members» and the problem of determining the subjects of the composition "business fragmentation").

Keywords: law, tax law, Tax Code of the Russian Federation, tax, value added tax, Federal Tax Service, tax audits, additional tax assessment, contract, freedom of contract, substantial tax obligation.
Голенев Вячеслав Вячеславович

Адвокат, Аспирант, Московский государственный юридический университет имени О.Е. Кутафина

vg@vgolenev.ru

Аннотация: Данная статья посвящена рассмотрению проблемы определения действительной налоговой обязанности. В Налоговом кодексе Российской Федерации данный вопрос остался неурегулированным, впоследствии это привело к распространенным судебным разбирательствам относительно реального размера налоговой обязанности. Суды по-разному применяли налогово-правовые нормы в ситуациях неопределенности относительно налоговой обязанности. В статье рассмотрены: проблема доначисления налога сверх цены договоров, зачет единого налога по упрощенной системе налогообложения в счет налога на прибыль при «дроблении бизнеса», и неправильное исчисление налоговым органом действительного размера налоговых обязательств по результатам налоговой проверки (неучет всех расходов «участников схемы»).

Ключевые слова: закон, налоговое право, Налоговый кодекс Российской Федерации, Налог, Налог на добавленную стоимость, Налог на прибыль организаций, Федеральная налоговая служба, налоговая проверка, доначисление налогов, действительная налоговая обязанность.

\section{Введение}

$\mathrm{H}$ алоговые органы выявляют случаи снижения налогоплательщиками своих налоговых обязательств путём создания ситуации, при которой видимость действий тех или лиц прикрывает фактическую деятельность самого налогоплательщика с целью получения, как правило, возможности пользоваться пониженным налогообложением посредством специальных налоговых режимов.

Для выявления указанных ситуаций налоговые органы используют расчетный метод, предусмотренный подпунктом 7 пункта 1 статьи 31 НК РФ [1], и определяют права и обязанности единого хозяйствующего субъекта исходя из подлинного экономического содержания осуществленных им операций (т.е. налогоплательщиком и подконтрольными ему лицами).

Однако, «объединяя» для целей налогообложения несколько организаций на базе проверяемого налогоплательщика в единый хозяйствующий субъект, возникает несколько проблем:
Как рассчитывать налоговую базу по налогу на прибыль теперь уже единого хозяйствующего субъекта?

Как учитывать расходы всех участников «дробления»?

Обязан ли налоговый орган учесть налоги, ранее уплаченные всеми участниками схемы? Кто вообще является участником такой «схемы»?

Какой должна быть налоговая обязанность «единого бизнеса» по НДС?

Наиболее часто указанные проблемы определения реального размера налоговой обязанности по налогу на прибыль организации встречаются в спорах о «дроблении бизнеса» [2]. Рассмотрим каждый из поставленных вопросов.

\section{Учитывается ^и уп^аченный подконтрольными налогоп^ательшиками обшествами на УСН еАиный налог УСН?}

Налоговые органы нередко вменяют налогоплатель- 
щику «дробление бизнеса» путем занижения налоговой базы налогу на прибыль путем искусственного включения в цепочку хозяйственных операций подконтрольных посредников, применяющих УСН при осуществлении спорных хозяйственных операций с конечными контрагентами.

Подконтрольные налогоплательщику посредники на УСН также уплачивают единый налог в связи с применением УСН с тех же доходов от спорных хозяйственных операций, с которых впоследствии налоговые органы взимают с налогоплательщика налог на прибыль.

Налоговой инспекции в таком случае сложно отрицать уплату единого налога подконтрольными налогоплательщику обществами на УСН с доходов от операций реализации товаров, работ и услуг. Реализуя право на применение расчетного метода, инспекция согласно буквальному толкованию подпункта 7 пункта 1 статьи 31 НК РФ должна определить расчетным путем именно суммы налога на прибыль единого хозяйствующего субъекта (налогоплательщика и подконтрольных обществ), уменьшив его на суммы уже уплаченного участниками дробления на УСН единого налога.

Однако налоговые органы нередко повторно облагают указанные доходы налогом на прибыль, вменяя его налогоплательщику, не учитывая ранее уплаченный единый налог УСН подконтрольными налогоплательщику участниками «дробления».

Вместе с тем, вмененный налогоплательщику налог на прибыль снижается на суммы уплаты подконтрольными обществами на УСН единого налога. Налог должен иметь экономическое основание (пункт 3 статьи 3 HК РФ). Экономический источник для взимания налога на прибыль с налогоплательщика - это вмененные ему доходы подконтрольных обществ на УСН от операций реализации товаров, работ или услуг.

Противоположный подход, нередко занимаемый налоговыми органами, формален. Он влечет двойное налогообложение одних и тех же операций с конечными контрагентами. По существу, с доходов по одним и тем же (с экономической точки зрения) операциям один раз уплачен единый налог обществами на УСН, во второй раз с этих же доходов с налогоплательщика взят налог на прибыль. Это неосновательное обогащение бюджета, хотя интересы казны не нарушены. Нарушается баланс частных и публичных интересов, неприкосновенность частной собственности [3], а также подход Высшего Арбитражного Суда Российской Федерации (далее - ВАС РФ) [4].

Поскольку оба налога (единый УСН и на прибыль) взяты с одних и тех же доходов за один налоговый период, то отсутствует ущерб бюджету в части уже уплаченного обществами на УСН единого налога. Обложение налогоплательщика налогом на прибыль подлежит уменьшению на суммы уже уплаченного участниками дробления на УСН единого налога.

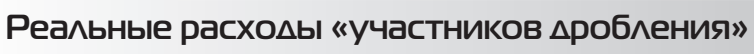 уменьшают вмененные налогоплательшику Аоходы «участников $А$ бобения»}

По мнению ФНС России, инспекция может применить расчетный метод определения налога на прибыль исключительно при отсутствии претензий к реальности операций налогоплательщика [5] (что касается и операций подконтрольных обществ как объединенных с налогоплательщиком). В налоговом законе запрет определения действительной налоговой обязанности («налоговой реконструкции» обязательства) по налогу на прибыль при «дроблении бизнеса» путем восстановления по платежным документам расходной части расчетным путем на основании подпункта 7 пункта 1 статьи 31 HK РФ отсутствует, что отмечается и в судебной практике [6].

Делая выводы о дроблении единого бизнеса, инспекция при отсутствии первичных документов использует право определить доходы «участников схемы» по налогу на прибыль расчетным путем. Следовательно, учитываются и полученные «участниками дробления» доходы, и понесенные ими расходы, к реальности которых нет претензий. Это допустимо и при отсутствии у «участников дробления» подтверждающих первичных документов, и при признании их ненадлежащими [7].

Формальный подход инспекции (полное непринятие затрат налогоплательщика и подконтрольных ему обществ на УСН по налогу на прибыль), в ситуации, когда затраты участников «дробления» на ведение деятельности для последующей реализации услуг конечным приобретателям продукции инспекцией не опровергнуты, неизбежно влечет искажение действительного размера обязательств по налогу на прибыль, поскольку неопровергнутые расходы единого бизнеса (налогоплательщик и подконтрольные общества) признаются реальными при исчислении налога (пункт 3 статьи 3 НК РФ) [8].

В случае, когда налоговый орган выявил занижение налоговой базы по налогу на прибыль организаций налогоплательщиком путем применения схемы дробления бизнеса, расходы взаимозависимых организаций на осуществление деятельности необходимо учитывать в полном объеме [9].

Таким образом, положения НК РФ, определяющие объект налогообложения и налоговую базу по налогу на прибыль организаций, не допускают возможности доначисления налогоплательщику сумм налогов в размере большем, чем это установлено законом, поскольку на- 
логоплательщики сами определяют размер налоговой обязанности исходя из фактических показателей хозяйственной деятельности налогоплательщика.

\section{НАФ^, страховые взносы, и иные «затратные» налоги, уплаченные обшествами на УСН ранее, также уменьшают обшую налоговую базу налогоп^ательшика по налогу на прибы^ь}

Учет прямых «затратных» налогов (например, налог на доходы физических лиц (далее - НДФЛ), налог на имущество организаций, транспортный налог, налог на добычу полезных ископаемых (далее - НДПИ) и т.д.) и страховых взносов, уплаченных ранее участниками «дробления» в состав налоговой базы налогоплательщика, не противоречит главе 22 НК РФ, и на их сумму можно уменьшить налогооблагаемую базу по налогу на прибыль.

Доначислив по результатам выездной налоговой проверки, например, страховые взносы или НДПИ, налоговый орган был уменьшить налоговую базу налогоплательщика по налогу на прибыль организаций на сумму доначисленного НДПИ или страховых взносов, если налог на прибыль организаций входил в предмет выездной налоговой проверки.

Вменив налогоплательщику доходы иных «участников дробления», с которых ими уже уплачены «затратные» налоги, инспекция обязана отразить их в расходах и уменьшить базу по налогу за тот же период [10].

\section{Какой Аолґна быть налоговая обязанность «еАиного бизнеса» по HАC?}

Несмотря на позицию ВАС РФ [11] о том, что если НДС в договоре не выделен, то он включен в цену, данный вывод был неочевиден по возможности его применения к ситуации, когда продавец теряет право пользования «спецрежимом» предшествующей датой, например, с УСН, при нарушении ограничений, поскольку Пленум ВАС РФ рассматривал ситуацию, когда продавец изначально является плательщиком НДС. А налогоплательщики-«спецрежимники» плательщиками НДС не являются и, соответственно, при заключении договоров НДС в цену в принципе заложить не вправе. Так что этот вопрос на уровне ВАС РФ остался нерешенным.

Более того, этот вопрос приобрел особую актуальность в связи с уже упомянутой проблемой принудительного «перевода» налогоплательщика с УСН на ОСН, в связи с чем инспекции доначисляют НДС «сверх» договорных цен, не производя извлечение НДС расчетным методом. Зачастую такие ситуации возникают при наличии у налоговых органов претензий к налогоплательщикам, связанных с возможным наличием схем «дробления бизнеса».

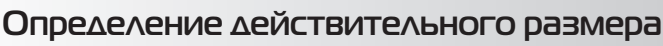 обязательств по НАС}

Доначисление инспекциями НДС сверх цены договоров между участниками схем «дробления бизнеса» и конечными контрагентами противоречит статьям 421, 424 ГК РФ, статье 164 НК РФ. НДС, из чего следует, что в силу свободы договора подлежит извлечению из цены сделок с контрагентами.

Зачастую инспекции и суды, имея в распоряжении все договоры (и изложенные в них цены) [12], заключенные между взаимозависимыми по отношению к налогоплательщику посредниками, которые используют УСН, и конечными сторонними контрагентами, протоколы допросов этих контрагентов (их должностных лиц), отказываются применять расчетный метод, указанный в статье 164 НК РФ и в пункте 17 Постановления № 33, для определения действительной налоговой обязанности налогоплательщика. Налоговые органы в таких ситуациях производят доначисление НДС сверх цены договоров участников «схемы» со сторонними контрагентами, вменяя доходную базу по указанным сделкам проверяемому лицу.

Однако экономическим источником для взимания НДС как части цены договора является встречное предоставление за продукцию, уплачиваемое налогоплательщику покупателем. При реализации товаров покупателю НДС не может исчисляться в сумме, не соответствующей реально сформированной цене. Иное означает незаконное взимание налога без переложения на потребителя, за счет иного экономического источника - собственного имущества продавца. Например, поставщик не может возложить на покупателя НДС, требуемый к уплате инспекцией, согласованная цена полагается как уже включающая НДС [13].

Определяя цену товара, стороны вправе указать в договоре на то, что сумма НДС включается или не включается в цену. В случае не выделения НДС в цене сделки в силу императивного указания закона сумма НДС извлекается из цены сделки. Таким образом, налоговые органы, не применяя, либо неверно применяя (к примеру, только к части операций налогоплательщика и/ или его взаимозависимых лиц), расчетный метод при доначислении НДС, вторгаются в сферу усмотрения сторон, в экономическую целесообразность заключения сделок по той или иной цене, нарушают свободу договора, изменяет коммерческие условия сделок, что недопустимо.

Определяя права и обязанности субъекта предпринимательской деятельности, необоснованно применявшего «спецрежим», как плательщика НДС, сумма налога по операциям реализации подлежит установлению, как 
если бы НДС изначально был бы предъявлен к уплате сторонним контрагентам по установленным с ними договорным ценам и полученной от них выручки, т.е., как правило - путем выделения НДС из выручки, с последующим применением расчетного метода определения (расчетной ставки) НДС. Сами по себе факты получения необоснованной налоговой выгоды не изменяют порядка определения недоимки и не влекут взимание налога в относительно большем размере [14]. Форма вины имеет значение при определении размера штрафа (пункты 1 и 2 статьи 122 НК РФ).

Таким образом, правомерным в указанных ситуациях является расчет действительного размера налоговых обязательств налогоплательщика исходя из применения ставки НДС 20/120 вместо прямого обложения спорных по своим налоговым последствиями хозяйственных операций по ставке $20 \%$ «сверху».

\section{ЛИТЕРАТУРА}

1. Налоговый кодекс Российской Федерации (часть первая) от 31.07.1998 № 146-Ф3 // СЗ РФ. № 31. 1998. Ст. 3824.

2. Пункты 3, 3.2 Письма ФНС России от 11.08.2017 № СА-4-7/15895@ «0 направлении обзора судебной практики, связанной с обжалованием налогоплательщиками ненормативных актов налоговых органов, вынесенных по результатам мероприятий налогового контроля, в ходе которых установлены факты получения необоснованной налоговой выгоды путем формального разделения (дробления) бизнеса и искусственного распределения выручки от осуществляемой деятельности на подконтрольных взаимозависимых лиц» // Документ опубликован не был. Источник - СПС «Консультант Плюс».

3. Статьи 8, 34 (часть 1), 35 (часть 1) Конституции России, Постановление Конституционного Суда Российской Федерации от 08.12.2017 № 39-П // Документ опубликован не был. Источник - СПС «Консультант Плюс».

4. Постановление Президиума ВАС РФ от 21.06.2005 № 2347/05 по делу ОАО «Винзавод „Воронежский“» // Документ опубликован не был. Источник - СПС «Консультант Плюс».

5. Пункт 8 Письма ФНС России от 22.08.2014 № СА-4-7/16692 «0 применении отдельных положений Постановления Пленума ВАС РФ 0т 30.07 .2013 № 57 «0 некоторых вопросах, возникающих при применении арбитражными судами части первой НК РФ» // Документ опубликован не был. Источник - СПС «Консультант Плюс».

6. Постановление Арбитражного суда Уральского округа от 23.01.2020 № Ф09-9691/19 по делу № А50-17644/2019 // Картотека арбитражных дел Верховного Суда Российской Федерации, URL: http://kad.arbitr.ru/Document/Pdf/7a554048-bbc1-485c-b478-a741b5f33403/01d67ae3-9406-4abb-a844b539b855c0da/A50-17644-2019_20200123_Reshenija_i_postanovlenija.pdf?isAddStamp=True (дата обращения 12.11.2020).

7. Подпункт 7 пункта 1 статьи 31 НК РФ, пункт 8 постановления Пленума ВАС РФ от 30.07.2013 № 57 «0 некоторых вопросах, возникающих при применении арбитражными судами части первой НК РФ»; пункты 3, 3.2 Письма ФНС России от 11.08.2017 № СА-4-7/15895@ «0 направлении обзора судебной практики, связанной с обжалованием налогоплательщиками ненормативных актов налоговых органов, вынесенных по результатам мероприятий налогового контроля, в ходе которых установлены факты получения необоснованной налоговой выгоды путем формального разделения (дробления) бизнеса и искусственного распределения выручки от осуществляемой деятельности на подконтрольных взаимозависимых лиц» // Документы опубликованы не были. Источник - СПС «Консультант Плюс».

8. Пункты 3, 7, 11 Постановления Постановление Пленума Высшего Арбитражного Суда Российской Федерации от 12.10 .2006 № 53 «06 оценке арбитражными судами обоснованности получения налогоплательщиком налоговой выгоды» // Вестник Высшего Арбитражного Суда Российской Федерации, 2006. № 12.

9. Определение Конституционного Суда Российской Федерации № 440-0 от 04.07.2017; Постановление Президиума ВАС РФ 0т 06.07.2010 №17152/09 по делу А29-5718/2008 «Молочный завод «Сыктывкарский», Постановление Арбитражного суда Восточно-Сибирского округа от 26.03 .2018 по делу АЗ3-29597/2016 «Вторичные ресурсы Красноярск», Постановление Арбитражного суда Московского округа 0т 05.02.2019 № Ф05-23958/2018 по делу № А40-195593/2017 // Документы опубликованы не были. Источник - СПС «Консультант Плюс».

10. Статьи 89, 101, 264 (подпункт 1 пункта 1), 272 (подпункт 1 пункта 7) НК РФ, пункт 32 0бзора судебной практики Верховного Суда Российской Федерации (ВС РФ) № 1 (2017) от 16.02.2017; Определения Судебной коллегии по экономическим спорам ВС РФ от 26.01.2017 № 305-КГ16-1347, от 30.11.2016 № 305-КГ16-10138; Постановления Президиума ВАС РФ от 06.07.2010 № 17152/09, от 02.10.2007 № 7379/07 // Документы опубликованы не были. Источник - СПС «Консультант Плюс».

11. Пункт 17 Постановления Пленума ВАС РФ от 30.05.2014 № 33 «0 некоторых вопросах, возникающих у арбитражных судов при рассмотрении дел, связанных с взиманием налога на добавленную стоимость» // электрон. ресурс, сайт системы арбитражных судов Российской Федерации, URL: http://www. arbitr.ru/arxiv/post_plenum/109469.html, (дата обращения 15.10.2020).

12.Дело № A40-36419/2019 Арбитражного суда города Москвы // электрон. ресурс, сайт системы арбитражных судов Российской Федерации, URL: https:// kad.arbitr.ru/Card/ac917483-2295-4955-9саa-се27с65с387с (дата обращения 15.10.2020).

13. Определения Судебной коллегии по экономическим спорам ВС РФ от 28.10.2019 № 305-ЭС19-9789 по делу №A41-48348/2017 (дело ИП Пяташова М.Е.), от 30.09.2019 № 307-ЭС19-8085, от 16.04.2019 № 302-КГ18-22744, от 23.11.2017 № 308-ЭС17-9467, от 24.11.2014 № 307-ЭС14-162 2015 // Документы опубликованы не были. Источник - СПС «Консультант Плюс». Дата обращения 09.10.2020; Решение Европейского суда справедливости от 07.11 .2013 по делам C-249/12, C-250/12 // Сайт Европейского суда справедливости. URL:https://eur-lex.europa.eu/legal-content/en/TXT/PDF/?uri=uriserv\%3A0J .C_.2012.243.01.0007.01.ENG. (дата обращения 09.10.2020); 
14. Определение Судебной коллегии по экономическим спорам ВС РФ от 28.10.2019 № 305-ЭС19-9789 по делу № А41-48348/2017; Постановление Пленума Высшего Арбитражного Суда Российской Федерации от 12.10.2006 № 53 «06 оценке арбитражными судами обоснованности получения налогоплательщиком налоговой выгоды» // «Вестник Высшего Арбитражного Суда Российской Федерации». 2006. № 12.

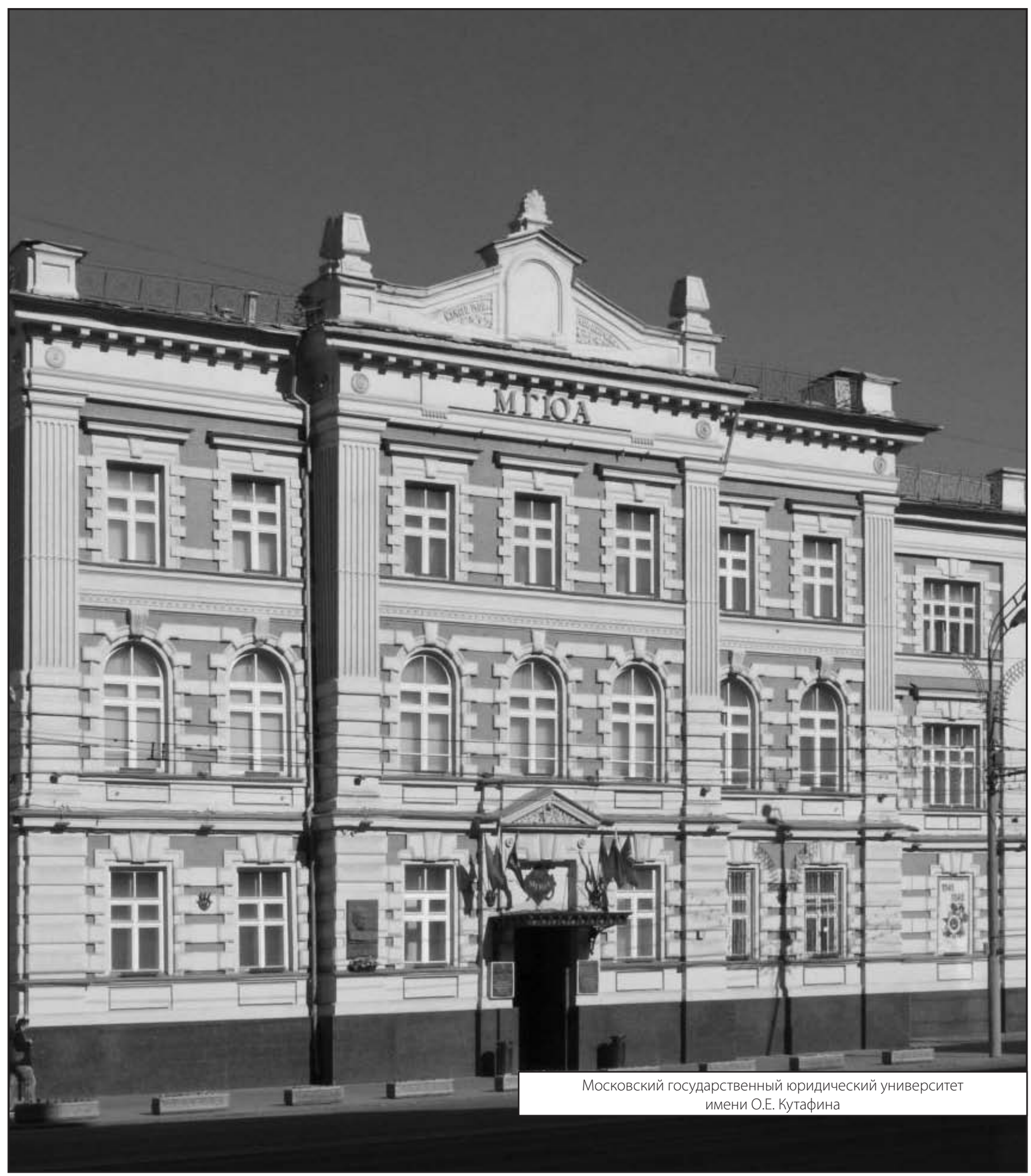

